\title{
Underwater Marine Domain Awareness for First Responders A Low Cost Approach
}

\author{
Justin E. Manley, Gary M. Mineart, Amy E. Sheridan, \\ Mitretek Systems, Falls Church, VA \\ http://www.mitretek.org, justin.manley@mitretek.org
}

\begin{abstract}
This paper describes research and field trials targeting underwater threats to homeland security and maritime infrastructure. The investigation emphasizes harbor/port facilities without the benefit of a large supporting military infrastructure and offers an affordable approach to this complex challenge. An analysis of the scope of maritime threats that highlights the threat of submerged improvised explosive devices (IEDs) deployed as sea mines was conducted. A new concept of operations for the detection and identification of such submerged IEDs is offered. The concept relies upon commercially available and relatively low-cost equipment along with currently deployed first responders in the maritime sectors. As such, it provides a logical potential solution to the current dilemma faced by the majority of accountable first responder organizations of needing expensive -- and likely unaffordable -- underwater surveillance equipment in U.S. port and harbor facilities. The threat assessment and employment concept are a focus of this presentation. Field trials conducted during August 2004 are also discussed.
\end{abstract}

\section{INTRODUCTION}

\section{A. Company Background}

Mitretek Systems is a nonprofit scientific research and system engineering organization that works exclusively on behalf of the American people. Mitretek conducts basic and applied research and undertakes systems engineering analyses to create scientific knowledge and technological solutions that strengthen the nation and benefit the public in the areas of criminal justice, environment, health, safety, energy, homeland security and counter-terrorism, space, transportation, and telecommunications.

Mitretek is distinguished from other scientific research and engineering companies by a position of complete independence and objectivity. Mitretek Systems refrains from establishing alliances for commercial purposes or competing with vendors and is free from organizational conflict of interest. Because of these organizational characteristics, Mitretek offers clients a unique capability to evaluate commercial technologies and industrial performance. This allows Mitretek to advise clients on technology products and services without even the appearance of bias or predilection for a particular solution.

\section{B. Mitretek Sponsored Research Program}

The Mitretek Sponsored Research (MSR) program allows Mitretek to advance science and technology, prepare for critical problems that clients will face in the future, advance corporate and staff capabilities, and further its public interest work. MSR funds are distributed through a competitive internal proposal process. Projects are usually designed to align with organizational strengths.

The MSR project described here is a result of the combination of two areas of interest at Mitretek. Homeland security, from biometrics to biological and chemical weapons management, is one area in which Mitretek regularly supports government clients. In the Oceanic Atmospheric and Space Systems Division, Mitretek provides extensive support to the National Oceanic and Atmospheric Administration (NOAA). All elements of NOAA are supported and there is a growing focus on marine technology. Recent Mitretek support for the search for submerged debris from the Space Shuttle Columbia and expeditions to the wreck of the RMS Titanic speak to this growing organizational capability. This MSR project combined the organization's strengths to focus on maritime security.

\section{MARITIME SECURITY THREATS}

\section{A. Research Process}

Due to funding and schedule limitations it was necessary to quickly evaluate the diverse maritime threats and select one for focused study. To do so, investigators attended conferences including the inaugural maritime port security symposium organized by the IEEE Oceanic Engineering Society. Additional research activities included literature search and personal investigations by members of the MSR team. Many Mitretek staff are former military officers and significant personal conversations allowed the team to rapidly focus its efforts. Contacts were made with U.S. Coast Guard, U.S. Navy and local maritime security agencies.

These investigations substantiated the initial premise of the MSR that subsea threats require the greatest level of effort. Surface attacks, such as that on the U.S.S. Cole or through shipping containers, are already the focus of significant attention. Investigations confirmed that within the subsea realm the two most significant threats are divers and clandestine mining or to borrow a term from the Iraq Occupation improvised explosive devices (IEDs). To quantify the problem and determine the most significant threat a weighted threat analysis was conducted. 


\section{B. Threat Analysis}

To equalize the threats a set of criteria were developed and each threat was assigned a score. The criteria included: casualties, economic impact, terror impact, ease of use (by terrorists), awareness of the threat (by security agencies), and national preparedness (to deter or recover from such an attack). Threats evaluated included, among others; nuclear/biological/chemical weapons in shipping containers, aircraft and small boat attacks against shipping, toxins in water supplies, and improvised underwater mines. Upon consideration of the potential economic consequences, and the relative lack of mine countermeasures equipment to support all U.S. ports, the threat of clandestine mines (underwater IEDs) was selected for further research. [1] This is primarily due to the level of effort already invested in diver defense as compared to that invested in harbor mine detection. The significant potential damage to the US economy (which remains heavily dependent on maritime trade) by even a failed mine attack also lends weight to this assessment. With the threat identified, the development of a potential operational concept for maritime monitoring commenced.

\section{OPERATIONS CONCEPT}

\section{A. Concept Overview}

Commercial technologies are available to address some of the U.S. maritime monitoring needs; however, for the most part they fall short of satisfying both the effectiveness and economic considerations of the bulk of the perceived port and harbor security user community, comprised principally of the local "first responders." Many existing systems are based on underwater detection technologies developed for the U.S. Navy and are not suitable for broad application to U.S. maritime security requirements. They are expensive and complex to deploy in numbers and are only found at diverse locations with a supporting military infrastructure.

Less expensive technologies are available to recreational boaters, divers, and fishermen, but they do not possess the technical capability that the maritime security community requires. Economical and effective technologies are required by local first responders so that the equipment can be acquired where needed and within the constraints of limited local budgets, but are sufficiently capable of detecting the underwater targets of interest.

The use of an affordable-and thus available to local entities-sidescan sonar system to conduct shipping route surveys in port and harbor areas identified as vulnerable to terrorist threats forms the basis for this operations concept (OPSCON). After the local port authority determines its priority vulnerability areas within its region of jurisdiction, an initial survey is conducted to provide a baseline description of submerged objects in vulnerable areas. Such an initial survey would serve to map the location of all of the inert detectable objects on the bottom. Periodic surveillance of these areas using the same survey routes and employing the same technologies would provide subsequent "snapshots" of the baseline survey area and would reveal the presence of any new, potentially threatening objects (e.g. improvised underwater mines) through the use of human or automated coherent change detection. The conduct of periodic surveys becomes a routine part of regular, recurring port and harbor patrols in the local area. The frequency of subsequent surveys would be dependent on the threat level, the size of the survey area, and the availability of assets. Upon location of a suspicious object, the survey vessel can quickly deploy lightweight remotely operated vehicle (ROV) technology with a variety of installed sensors to quickly assess the threat without putting divers in jeopardy. The port authority then directs the appropriate notification, further assessment and identification if necessary, removal, or neutralization of the suspected IEDs or mines. A graphical representation of this OPSCON is provided in Fig 1.

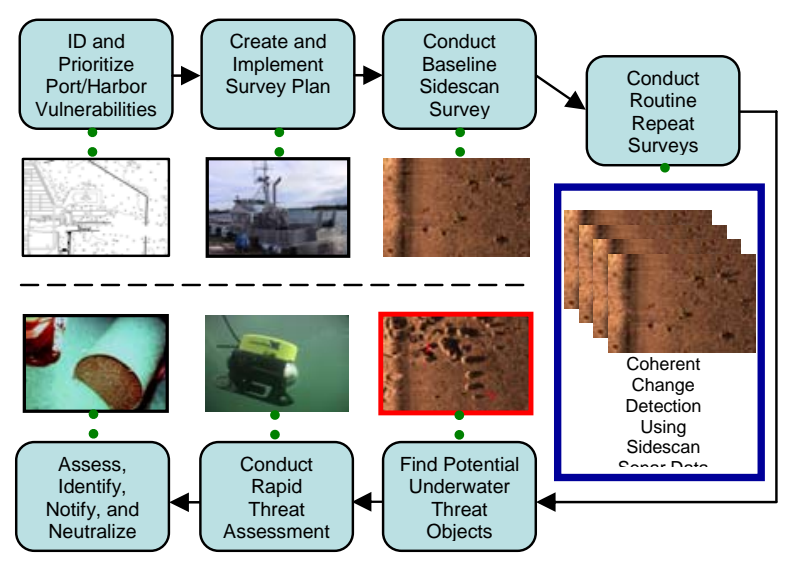

Fig 1. The Maritime Security OPSCON

\section{B. Technology Suite}

A core assumption of the OPSCON developed is the availability of effective, but also inexpensive, sidescan sonar and ROV systems. Low cost is required as any eventual wide application of this OPSCON would likely see each port deploying multiple copies of this technology suite. The US Coast Guard has identified 58 economic and militarily strategic ports. [2] Beyond this there are hundreds of 
smaller ports that might be targeted. Clearly wide use of this OPSCON demands low costs for capital equipment. Low costs also allow local first responders to pursue acquisition and deployment of such tools using their own local funds rather than awaiting large federal spending allocations.

A technology suite was identified to include: 1) a small ROV, 2) low-cost sidescan sonar, 3) GPS navigation, and 4) laptop PC for data acquisition. Upon review of commercially available systems, a Seabotix LBV, Fig 2, and an Imagenex SportScan sonar, Fig 3, were selected as the best choices for this OPSCON. While there are other ROVs available in this size/price range the Seabotix vehicle is generally more sophisticated and offers greater flexibility for additional sensor integration if required. The Imagenex sonar, while not unique technology, has broken a significant price barrier through miniaturization of digital electronics. The next lowest cost side-scan sonar is roughly five times as expensive. Both of these tools are low cost and, in comparison to their "bigger brothers," unsophisticated. However, they also represent a new paradigm for marine technology and fit the OPSCON very well.

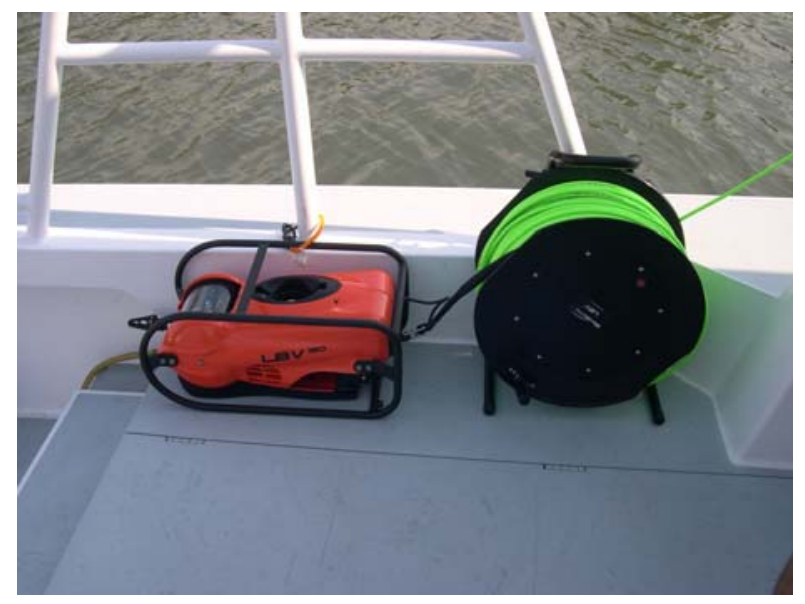

Fig 2: The Seabotix LBV Remotely Operated Vehicle

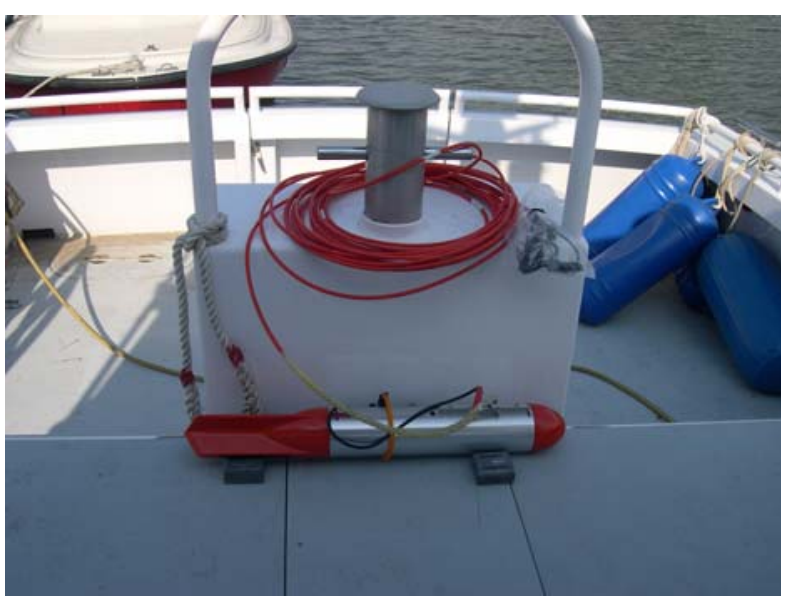

Fig 3: The Imagenex SportScan Sidecan Sonar

\section{FIELD TESTS}

To verify the viability of both the OPSCON and the technology suite a series of field tests were conducted. These test occurred August $3^{\text {rd }}$ through $13^{\text {th }}, 2004$ on Lake Michigan in the Chicago area.

\section{A. Technology Analysis}

The first phase of the field program was careful testing of the technology suite. To evaluate the sonar it was used to image the bottom of Lake Michigan, the Chicago River, and Waukegan Harbor in Lake County, Illinois. These baseline surveys demonstrated the general imaging capabilities of the sonar. Wrecks ranging from 50 to over 200 feet provided excellent targets and confirmed that the sonar was operating to its manufacturer's specifications. Fig 4 shows a sonar image of the Wells Burt a schooner sunk off Chicago nearly 100 years ago. These initial surveys were all performed from a 36 foot vessel, Fig 5, similar to those used as patrol boats. In fact, the vessel used is a sister ship to two patrol craft used by the Illinois Wildlife Conservation Police. The selection of this vessel offered an excellent simulation of a likely first responder patrol boat.

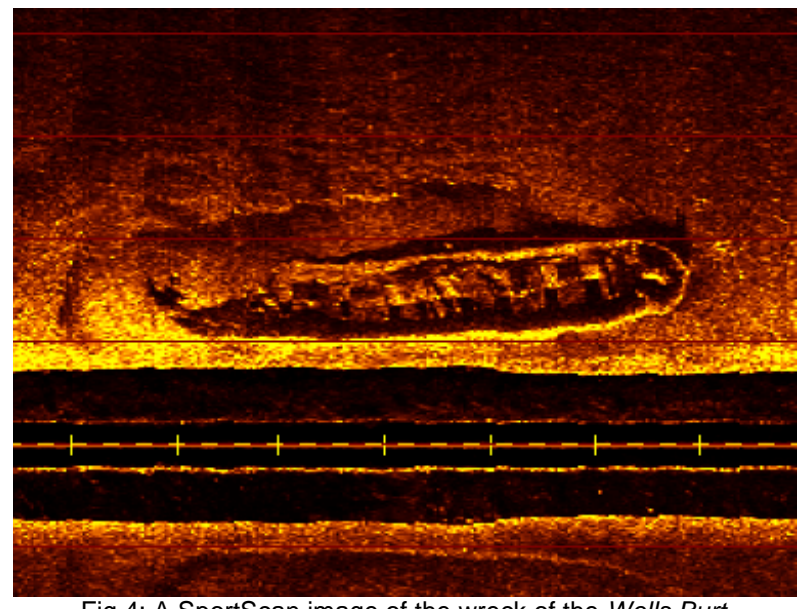

Fig 4: A SportScan image of the wreck of the Wells Burt

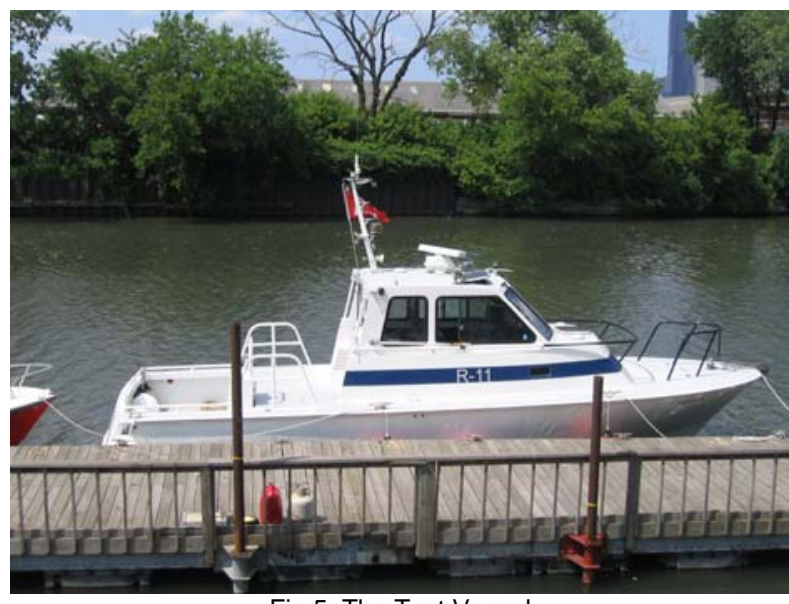

Fig 5: The Test Vesse 
Once the investigators were satisfied with the general performance of the sonar a series of specific target detection trials were conducted. The objective was to rigorously define the ability of the SportScan sonar to image likely clandestine mines. Targets in the range included a series of radar reflectors suspended by an air bag, a spar buoy and its anchor, and a 55 gallon steel drum which was allowed to fill with water. Fig 6 shows the drum used. The positions of all targets were carefully noted and several surveys were conducted using both the high (800 kHz) and low $(330 \mathrm{kHz})$ frequencies available on the sonar. Differing range scales were also used. The complete analysis of these runs [3] showed that the SportScan had difficulty imaging the water filled drum.

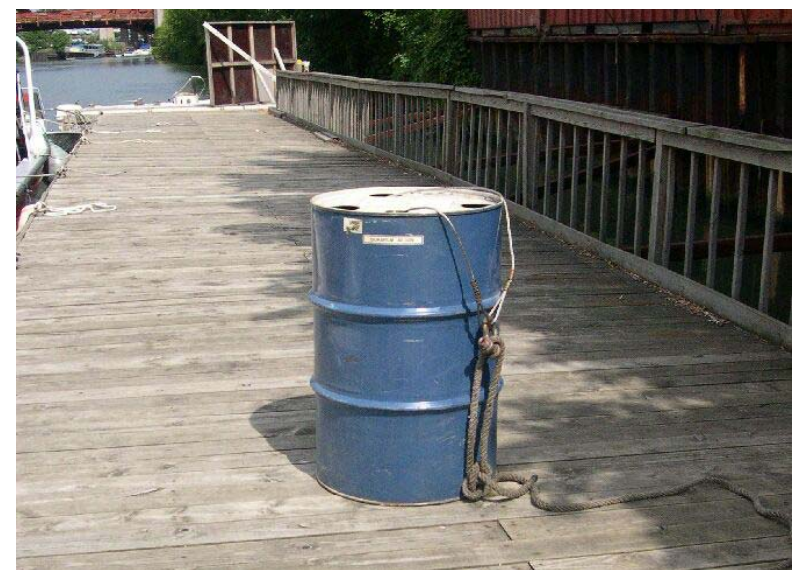

Fig 6: The drum used in sonar trials

While the failure of the SportScan to image the drum during these tests was disappointing it was not entirely unexpected. Filling the drum with water rather than a denser substance, that might more closely approximate explosives, was a deliberate choice. Providing an especially challenging target would provide the most rigorous test. It should be noted that during these runs the SportScan did in fact show a return for the drum. This return, however, was not distinctive enough to be readily apparent amongst the background clutter of the test range on the bottom of the Chicago River. A cluttered range was also a deliberate choice to more closely simulate the conditions of the OPSCON.

In order to eliminate possible sources of error, an additional series of test runs were made specifically over the drum. In this case the sonar was moved from the 36 foot vessel to a smaller 25 foot boat. The notable difference between the two was their idle speeds. The larger vessel had a minimum speed of 3.0 to 3.5 knots. The smaller vessel could make headway at 1.0 to 1.5 knots. As the SportScan default speed, when GPS speed corrections are unavailable, is 3.0 knots it was expected that this speed difference would not change the results.

This was incorrect. At the slower speed the water filled drum was easily distinguishable from the background. This is apparent in Fig 7 where the drum is marked by the blue circle. The length width and shadow height of this feature are all consistent with the drum's dimensions. The change in speed was not the only change as the towfish was deployed over the bow of the smaller vessel. This approach was chosen to protect the towfish from exposure to the outboard motors on the smaller vessel. In both cases the towfish was "flying" at a similar height off the bottom.

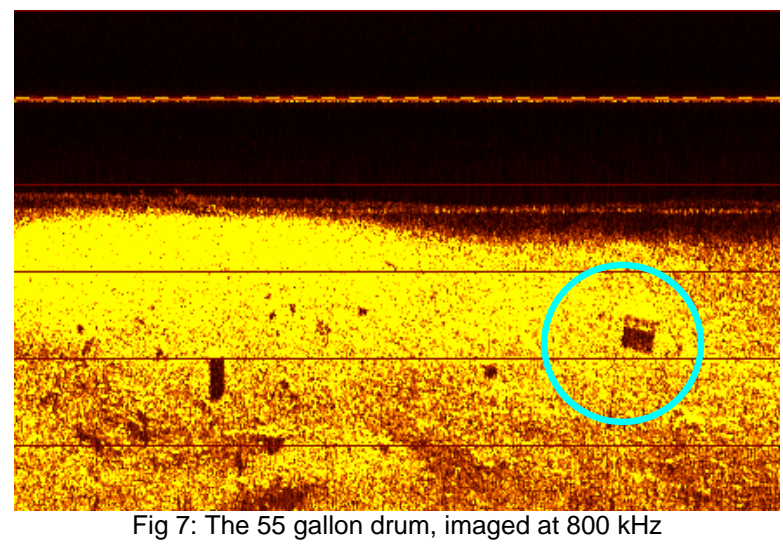

Unfortunately, there was not sufficient field time available to isolate the exact change that yielded the improved performance. It is most likely a result of the slower towing speed allowing more ensonification over the target. While further work could provide additional characterization of this result it was sufficient to identify a configuration that was effective at detecting this challenging target.

Before the OPSCON evaluation could begin an analysis of the ROV performance was required. To establish the capabilities of the ROV and its suitability to the OPSCON it was operated in the Chicago River, where visibility was low and currents could exceed $1.0 \mathrm{knot}$, and in the open waters of Lake Michigan. In the lake visibility improved but currents still presented a challenge. On the river the Seabotix LBV was easily able to make headway against the current even with a large loop of tether in the current.

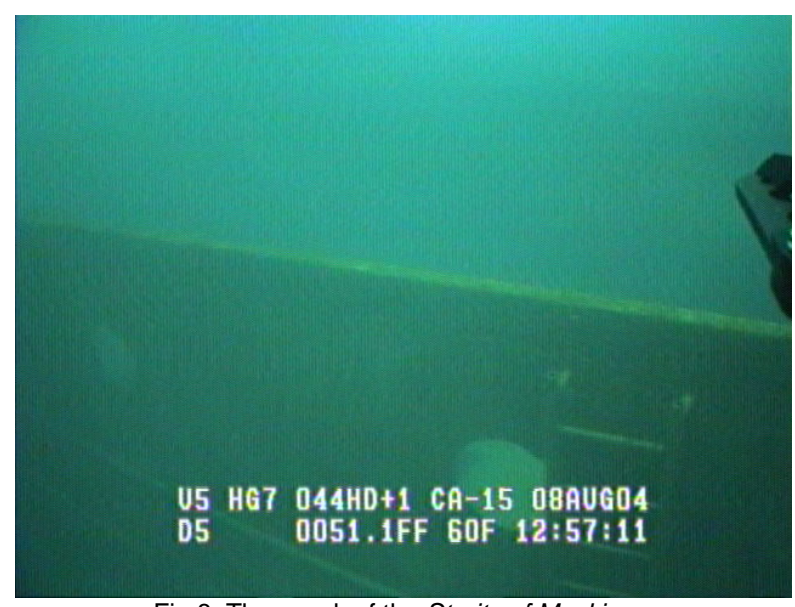

Fig 8: The wreck of the Straits of Mackinaw 
At depth over the wreck of the Straits of Mackinaw the Seabotix ROV was able to explore the wreck despite currents of 1.0 to 2.0 knots. Fig 8 is a frame grab from the ROV video which shows a porthole and ladder on the side of the wreck.

In a variety of conditions the ROV demonstrated its ability to inspect wrecks, hulls, seawalls and other open or protected water regions. The remaining question was how local first responders would react to the technology.

\section{B. Operations Concept Analysis}

To evaluate the OPSCON, maritime first responders were given the opportunity to work directly with the technology. Both the Lake County Sheriff and the Chicago Police Department marine units took advantage of the opportunity. Officers from both units were able to rapidly learn the principles of both technologies and effectively operate the ROV.

The Chicago Police, Fig 9, were interested in using the ROV for inspection tasks in waters that might be hazardous to divers.

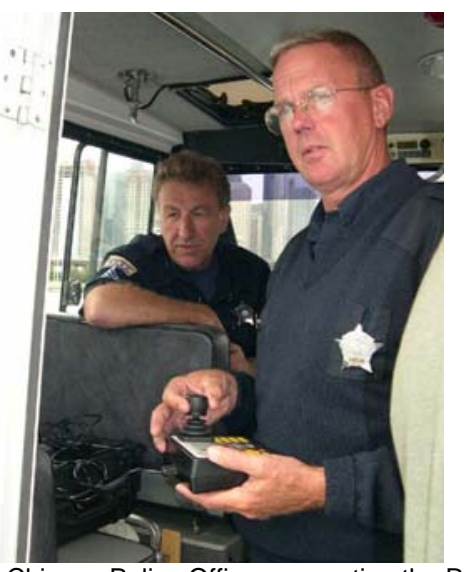

Fig 9: Chicago Police Officers operating the ROV

In addition to examining river and lake bottoms for evidence they were also interested in using the ROV for hull inspections. Fig 10 shows the underside of a vessel in moderate visibility waters.

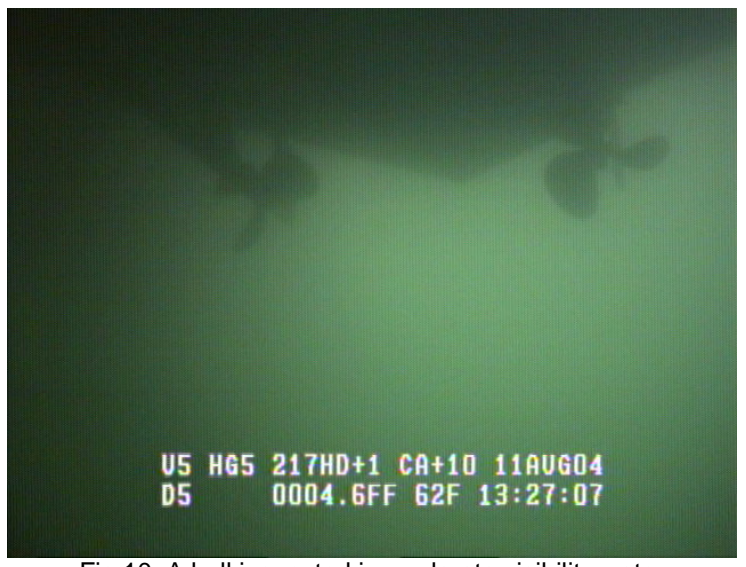

Fig 10: A hull inspected in moderate visibility water
Fig 11 shows a frame grab from a wall inspection in Calumet harbor, the primary commercial shipping port in the Chicago area. While Fig 10 demonstrates the exceptional quality available in clear conditions, Fig 11 shows that even in lower visibility the ROV was able to collect useful images. The fish visible in the frame (near the ROV manipulator on the upper right) reveals that a field of view of several feet is possible. Both units recognized the potential benefit of adding a scanning sonar to the ROV and believed that the incremental cost was acceptable.

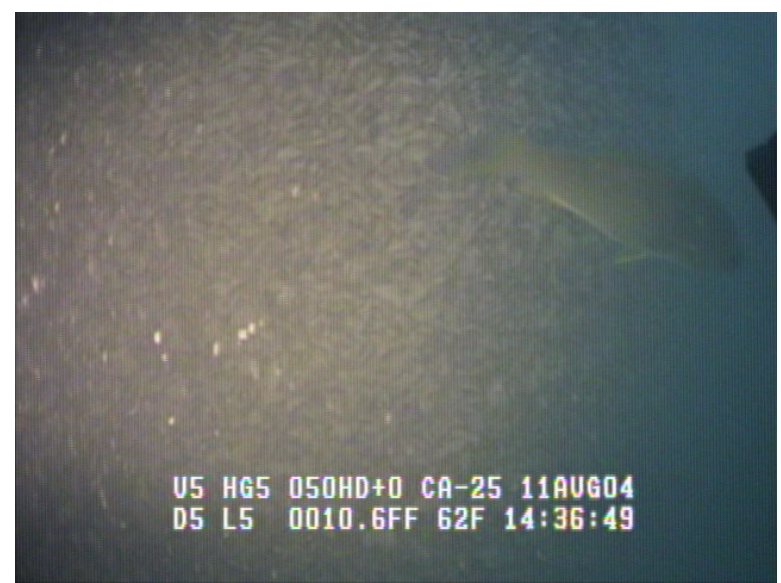

Fig 11: A seawall inspected in Calumet harbor

In addition to demonstrations of the ROV'S capabilities both units were interested in the potential of the sidescan sonar. The Chicago Police were especially interested in sonar imagery taken in the Chicago River. One particular portion of the river passes under a highway overpass. It was suspected that this area was a dumping ground for automobiles. The SportScan did in fact reveal several likely targets in this area, Fig 12. While no confirmation is available that these are in fact dumped cars the sonar signatures convinced the police they were correct.

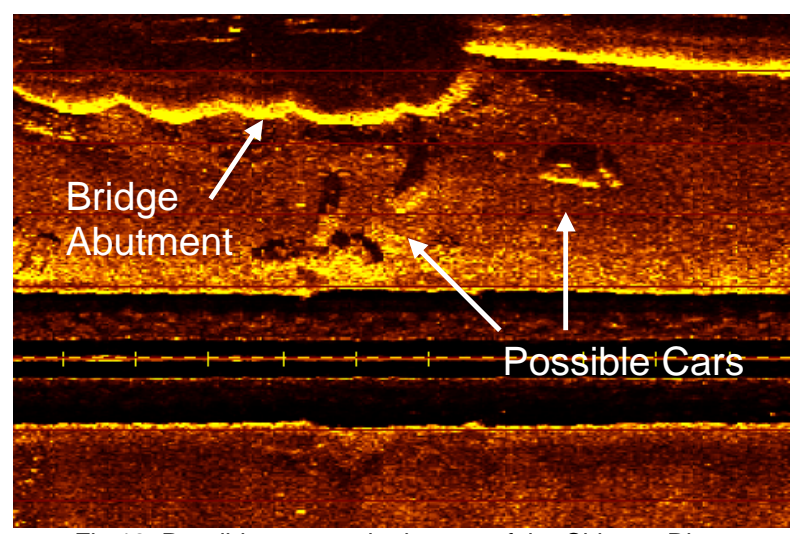

Fig 12: Possible cars on the bottom of the Chicago River

The Lake County officers were also interested in the ROV and the sonar. To demonstrate the ease of use of the SportScan sonar the team deployed it from one of the Sheriff's own vessels. In approximately 30 minutes the Sheriff's vessel was equipped and surveying Waukegan Harbor, Fig 13. 


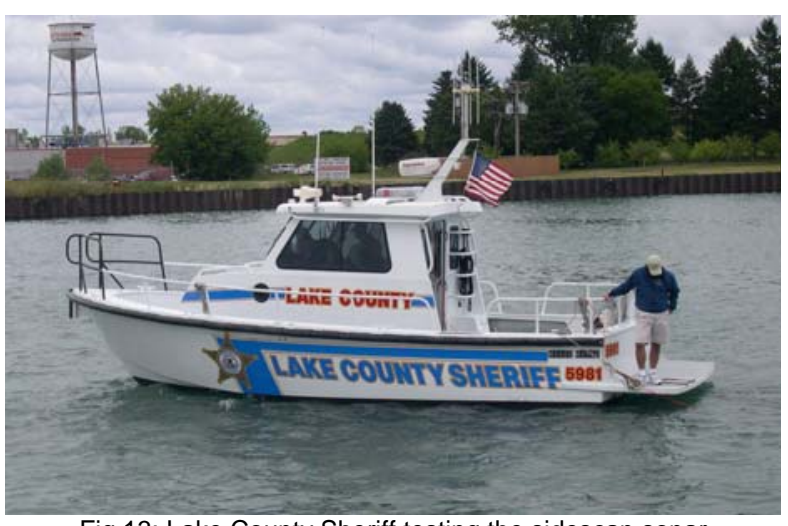

Fig 13: Lake County Sheriff testing the sidescan sonar

\section{CONCLUSIONS}

This project demonstrated that low cost commercial ROVs and sidescan sonar can meet the needs of maritime first responders in local agencies. The addition of a scanning sonar to the technology suite would be recommended to improve the ROV's performance in low visibility conditions. With such an upgrade the total cost for one set of equipment would be approximately $\$ 50,000$ USD.

Through interactions with the OPSCON target community it was possible to determine that local marine safety and security officers have the aptitude to use such tools. They were also readily able to envision their use in both their standard duties and a maritime security role. While neither unit currently has any regularly assigned homeland security role they could fill such duties if equipped with the proper technology.

Mitretek Systems plans to continue this line of research and will extrapolate the results of these tests to a national scale. Case studies of various ports will analyze the applicability of this OPSCON across the nation. Assuming this additional research is also positive, a blueprint for a national underwater "neighborhood watch" will be available to improve the Nation's port and harbor security.

\section{References}

[1] J. Manley, "Integrated Technologies for Maritime Domain Awareness," Internal Briefing, Mitretek Systems, Falls Church, VA, March 2004.

[2] LCDR S. Shapiro, "Maritime Homeland Security," USCG Port Security Directorate briefing, 2002, available:

http://gulliver.trb.org/publications/mb/2002Ports/01Shapiro.pdf

[3] J. Manley, G. Mineart, A. Sheridan, "Integrated Technologies for Maritime Domain Awareness, Field Results," Internal Report, Mitretek Systems, Falls Church, VA, September 2004. 